\title{
The applicability of FCFF method evaluating an enterprise of Real Estate segment
}

\author{
Jaromír Vrbka ${ }^{1, *}$ and Pavla Vitková $^{1}$ \\ ${ }^{1}$ Institute of Technology and Business, School of Expertness and Valuation, Okružní 517/10, 37001 \\ České Budějovice, Czech Republic
}

\begin{abstract}
The article aims at evaluating a specific enterprise of the Real Estate segment using FCFF (Free Cash Flow to Firm) method. This technique determines the company's value through free cash flows. Enterprise valuation presents a distinct discipline requiring appraiser's deep understanding not only of the evaluated enterprise but also other external decisive influences. The theoretical part focuses on calculation procedures using The CAPM (Capital Asset Pricing Model) model quantifying separate variables that determine discount rates. The suggested technique deals with specific financial data of the company and is applicable in evaluating small and medium-sized enterprises.

Key words: enterprise valuation, FCFF, CAPM, cash flow, real estate, risk rate
\end{abstract}

\section{Introduction}

Enterprise valuation currently presents an extensively discussed issue in terms of economy and finance. Adopting a good method facilitates a thorough valuation of the enterprise, which is a very important factor regarding finance as companies certainly need equity evaluated for purposes such as loans, mergers and seeking or making public tenders. Developed economies use the technique of property valuation upon business mergers or acquisitions. On the other hand, developing countries apply this method to foreign investments in a specific country. Growing globalization, market liberalization and cutthroat competition prevent academic workers, company owners, and managers of advisory companies from precisely setting the value of equity of the enterprise [1-2].

Successful determination of the value of an enterprise is subject to many aspects. Thriving companies have a high market value guaranteed only by long-term and complete stabilization, which is achieved by permanent financial balance and continuously positive economic results [3-4]. Financial soundness has a priority as yield methods apply only to the future potential of the company [5]. Upon conducting analyses, prognosis generators, e.g. revenue estimates, operating profit margin, working capital and investments, will deliver the valuation. These generators carry out a preliminary valuation of the company which is, however, informative and its value indicates only provisional estimate [6].

* Corresponding author: vrbka@mail.vstecb.cz 
The property valuation method presents a distinct and complex discipline, considering the enterprise value from different aspects. The first depends on the purpose of the valuation and the appraising subject; the second being the reason [7].

The article aims at applying the method of valuation by discount free cash flows conducted on a specific enterprise. The result suggests strong sides and shortcomings of the technique to recommend the use of this method of valuation.

\section{Literature Research}

Dong Yangig [8] regards the company valuation as a part of an economic discipline that grows in importance within the economic transformation. Free cash flow method contains information that may objectively and comprehensively reflect the ability of enterprises to generate the value, but also help companies clearly understand their market value. The market appraisal depends on the profit rate from previous periods and corporations' current free cash flow [9]. The company value should thereby be of vital interest to future investors and managers. Measuring performance plays an essential role in the companies' value generation [10]. The most challenging task for the management is to adopt an effective method of assessing accomplishments, which will precisely measure the performance of the organization within a specific period. The traditional accounting measures were subject to criticism for failing to consider overall capital costs [11-12].

Dong [8] suggest methods of calculating the free cash flow in a text focused on analysing and appraising enterprises. The analysis of the balance-sheet report and valuation, in general, begins with business operations, i.e. units of accounts dealing with enterprise's primary activities to generate incomes and subsequent addition of the value of its monies and other financial assets. The author claims that the valuation of a company's property ownership should be the same for both methods of calculating the free cash flow. The analyst should, however, improve the technique to calculate capital costs (WACC), which will allow discounting of estimated free cash flows to the current value of the company.

If free cash flow (FCF) value or the value of the cash flow is relevant, and managers submit prognoses to investors, Hoque and Rakow [13] constructed a model demonstrating the influence of these prognoses on the value of the company. On the other hand, corporations with positive free cash flows and high performance pressure their management to reduce profits to avoid the interest of state institutions and tend to lower or cover their performance by profit management.

Shaikh [14] observe the diversion from traditional performance-related assessments based on accounting to performance-related values. Economic value added (EVA) and FCF are reliable indicators showing performance that considers values derived from a long-term goal of accumulating wealth, as contrasted to a short-term approach to maximize the profit [15-18]. Performance indicators built on values (including without limitation EVA) are superior to traditional ratios such as earnings per share (EPS), return on equity (ROE), return on assets (ROA) etc. These do not express value creation and, as they closely relate to accounting, can be effectively processed by senior workers and therefore are not very useful for shareholders as reliable performance ratios.

It is crucial to understand the relationship between different performance values and empirically verify the conceptual equivalence of the FCF and EVA [19-20]. In his analysis, Shaikh [14] proves a strong correlation between FCF and EVA. EVA and FCF are favourably close, which means they yield similar results to measure the performance of the enterprise. Discounting of carefully defined FCF is conceptually equivalent to the discount of economic profits (EVA) for the output and decision-making process.

Although there are lots of approaches to determine the value of the company, experts entertain conflicting opinions as to the efficient method of valuation. The methodological 
part thereby shows a financial model suitable for calculating capital costs and value of the company, considering only components essential to the operation and capacity of the enterprise; i.e. those which reflect the financial soundness of the enterprise.

\section{Data and methods}

The case study analysed a medium-sized enterprise, "Malá Šárka plc.”, with publicly available financial data from 2015-2018.

Determining the value of the enterprise employs the method of discounted free cash flow FCFF. The technique involves all cash flows of owners and creditors generated by the enterprise from operational assets, providing the company's value as a whole. What follows is the subtraction of the foreign capital to achieve the value of equity. Calculations proceed in two steps. The first part deals with discount FCFF followed by subtracting the value from the foreign capital to evaluate the equity of the enterprise.

The first step involves determining the earnings of the enterprise before paying taxes and interests.

$$
E B I T=E B T+I
$$

EBIT: $\quad$ Earnings before Interest and Taxes,

EBT: $\quad$ Earning before Taxes,

I: $\quad$ Interest.

To determine FCFF we modify EBIT values. The first phase monitors periods reduced by the tax rate for a specific year, amortization and other costs. The second phase considers investments in operational working capital and investments in fixed assets.

The final value of the formula for calculating FCFF is determined according to aforesaid operations.

$$
F C F F=E B I T *(1-t)+A-I N V
$$

$t: \quad$ Tax rate,

A: $\quad$ Amortization,

INV: $\quad$ Long-Term Investments + Invests in Working Capital.

We further determine WACC by CAPM, which fixes $r_{e}-$ costs of equity calculated by risk-free profit rate on the market, risk rate and equity risk premium. The risk-free rate on the market is based on the interest rate of long-term and medium-term government bonds [21]. Specific values arise from issuing calendars of 2015, 2016, 2017, 2018 available on the internet portal of the Ministry of Finance of the CZ. Beta Parameter is determined on the value accessible on websites of Professor A. Damodaran. Our case explores Real estate operations \& services. The equity risk premium also originates from websites of the respective professor as a value of the entire Czech Republic valid for 2015, 2016, 2017, 2018.

$$
r_{e}=r_{f}+\beta *\left(r_{m}-r_{f}\right)
$$

$r_{f}$. Risk-free Rate,

$\beta$ : $\quad$ Volatility of Company's Stock Price in the Capital Market,

$r_{m}-r_{f}: \quad$ Equity Risk Premium.

To determine weighted costs of the total market value of the company, we apply a formula considering both - the equity and foreign capital. 


$$
\mathrm{WACC}=\frac{E}{C} * r_{e}+\frac{D}{C} * r_{d} *(1-t)
$$

$\begin{array}{ll}r_{e}: & \text { Cost of Equity, } \\ r_{d:} & \text { Cost of Debt, } \\ C: & \text { Total Market Value of the company, } \\ D: & \text { Market Value of the company's debt, } \\ E: & \text { Market Value of the company's equity, } \\ t: & \text { Corporate tax rate. }\end{array}$

The first step encompasses determining FCFF value for individual years and discount WACC value to calculate the enterprise value.

$$
E V 1=\sum_{t=1}^{t=n} \frac{F C F F_{t}}{(1+W A C C)^{t}}
$$

$$
\begin{array}{ll}
E V 1: & \text { Enterprise Value, } \\
t: & \text { the Specified Year, } \\
n: & \text { the Number of Years. }
\end{array}
$$

The second step consists in fixing a going value of the company. This calculation uses Gordon Model including growth rate g, assessing gross national product (GNP) growth and inflation. The essential requirement is also a steady growth of cash flows.

$$
F C F F_{n+1}=F C F F_{t} *(1+g)
$$

g: $\quad$ Growth Rate of FCFF.

The specific discount rate is derived from future costs of the capital WACC, requiring the enterprise's stability in cash flow growth.

The applied formula is as follows:

$$
G V=\frac{F C F F_{n+1}}{W A C C-g}
$$

GV: $\quad$ Going Value

The total value of the enterprise involves the sum of partial results of both steps.

$$
E V=\sum_{t=1}^{t=n} \frac{F C F F_{t}}{(1+W A C C)^{t}}+\frac{F C F F_{n+1}}{W A C C-g}
$$
$E V$ :
$t: \quad$ the Specified Year last year of first step,
Enterprise Value,
$n: \quad$ the Number of Years in first step,
g: $\quad$ Perpetual Grow.

\section{Results}

"Malá Š́rka plc." was the selected enterprise for the application of accounting data and validation of the devised method. The company's core business is to provide services and is located in Prague.

\subsection{Enterprise value in the first step}

Publicly available balance-sheet statements reported the profit rate before interest and EBIT tax deductions. 
Table 1. Calculating earnings before interest and tax payments (EBIT) within 2015-2018 (in thousands CZK)

\begin{tabular}{|l|r|r|r|r|}
\hline \multicolumn{1}{|c|}{ Value } & \multicolumn{1}{c|}{$\mathbf{2 0 1 5}$} & \multicolumn{1}{c|}{$\mathbf{2 0 1 6}$} & \multicolumn{1}{c|}{$\mathbf{2 0 1 7}$} & \multicolumn{1}{c|}{$\mathbf{2 0 1 8}$} \\
\hline Economic result before taxation $(+)$ & 87 & 196 & 233 & 194 \\
\hline Interest costs $(+)$ & 0 & 0 & 0 & 0 \\
\hline EBIT & 87 & 196 & 233 & 194 \\
\hline
\end{tabular}

Sources: Own processing.

Table 1 depicts the perpetual growth of earnings of the enterprise - the economic result before taxation and, subsequently, before paying interests and taxes (EBIT). The year of 2017 saw an increase in its earnings caused by revenue growth for provided services.

Table 2. Values of free cash flows (FCFF) within 2015-2018 (in thousands CZK)

\begin{tabular}{|l|r|r|r|r|}
\hline \multicolumn{1}{|c|}{ Value } & \multicolumn{1}{c|}{$\mathbf{2 0 1 5}$} & \multicolumn{1}{c|}{$\mathbf{2 0 1 6}$} & \multicolumn{1}{c|}{$\mathbf{2 0 1 7}$} & \multicolumn{1}{c|}{$\mathbf{2 0 1 8}$} \\
\hline EBIT & 87 & 196 & 233 & 194 \\
\hline Tax - tax rate t=19\% (-) & 17 & 37 & 44 & 37 \\
\hline Amortization (+) & 5612 & 5983 & 6026 & 6264 \\
\hline Working capital change (-) & $\mathrm{n} / \mathrm{a}$ & 313 & 524 & 477 \\
\hline Investment changes in fixed assets (-) & $\mathrm{n} / \mathrm{a}$ & 5759 & 5622 & 5879 \\
\hline FCFF & $\mathrm{n} / \mathrm{a}$ & 70 & 69 & 65 \\
\hline
\end{tabular}

Sources: Own processing.

Table 2 suggests the free Cash Flow rate. The tax rate 19\% and company's amortization is overall equal, with the only fluctuation in 2017 caused by revenue growth and subsequently influenced by the change in the working capital.

Table 3 shows statistical values within separate periods as published in annual balancesheet reports within the business sphere of the Ministry of Industry and Trade. Beta Coefficient and risk premiums are available on websites of Professor A. Damodaran. Calculations determined the rate of average capital costs paid by the company to ensure its business activities (WACC). Furthermore, costs of capital and equity fixed WACC for individual periods.

Table 3. Weighted average capital costs (WACC) within 2015-2018 (in thousands CZK)

\begin{tabular}{|l|r|r|r|r|}
\hline \multicolumn{1}{|c|}{ Value } & \multicolumn{1}{c|}{$\mathbf{2 0 1 5}$} & \multicolumn{1}{c|}{$\mathbf{2 0 1 6}$} & \multicolumn{1}{c|}{$\mathbf{2 0 1 7}$} & \multicolumn{1}{c|}{$\mathbf{2 0 1 8}$} \\
\hline Surcharge for the financial stability; $\mathrm{r}_{\mathrm{f}}$ & $0.54 \%$ & $0.46 \%$ & $0.79 \%$ & $1.90 \%$ \\
\hline Beta & 0.89 & 0.99 & 0.62 & 0.80 \\
\hline Premium for market risk in CZ; rm-rf & $5.60 \%$ & $6.30 \%$ & $6.20 \%$ & $5.90 \%$ \\
\hline Equity yield; r & $5.52 \%$ & $6.70 \%$ & $4.63 \%$ & $6.62 \%$ \\
\hline
\end{tabular}




\begin{tabular}{|l|r|r|r|r|} 
Cost of debt; rd & $0.00 \%$ & $0.00 \%$ & $0.00 \%$ & $0.00 \%$ \\
\hline Market value of the company's debt; D & 0 & 0 & 0 & 0 \\
\hline Market value of the company's equity; E & 34287 & 34376 & 34496 & 34588 \\
\hline Total market value of the company; C & 34287 & 34376 & 34496 & 34588 \\
\hline WACC & $5,52 \%$ & $6,70 \%$ & $4,63 \%$ & $6,62 \%$ \\
\hline
\end{tabular}

Sources: Own processing.

Table 4. Enterprise value EV in the first step (in thousands CZK)

\begin{tabular}{|l|r|r|r|r|}
\hline \multicolumn{1}{|c|}{$\mathbf{1}^{\text {st }}$ step } & \multicolumn{1}{c|}{$\mathbf{2 0 1 5}$} & \multicolumn{1}{c|}{$\mathbf{2 0 1 6}$} & \multicolumn{1}{c|}{$\mathbf{2 0 1 7}$} & \multicolumn{1}{c|}{$\mathbf{2 0 1 8}$} \\
\hline FCFF & & 70 & 69 & 65 \\
\hline WACC & $5.52 \%$ & $6.70 \%$ & $4.63 \%$ & $6.62 \%$ \\
\hline EV $1^{\text {st }}$ step & & 65 & 63 & 54 \\
\hline EV $1^{\text {st }}$ step & \multicolumn{4}{|c}{$\mathbf{1 8 2}$} \\
\hline
\end{tabular}

Sources: Own processing.

Table 4 demonstrates enterprise values in the first step of the calculation. Discount rates applied to calculate weighted average capital costs. The resulted value discounted and subsequently added up free cash flows FFCF.

\subsection{Calculating values in the second step}

The resulting value of free cash flows for the following period $\left(\mathrm{FCFF}_{\mathrm{n}+1}\right)$ and the growth rate is based on the estimated year-to-year GNP growth and inflation. GNP rate $2.4 \%$ and inflation $2.6 \%$ was built on statistical data with final sum $5.2 \%$.

$$
F C F F 2019=65 *(1+0.052)=69 \text { thousands } C Z K
$$

The going value for the consecutive year equals to: $\mathrm{GV}=4,826$ thousands CZK.

\subsection{Total market value of the company} steps:

The total market value of the company is given by summarizing partial results of both

$$
E V=182+3982=4,164 \text { thousands } C Z K
$$

\section{Discussion}

To valuate an enterprise using Discount Free Cash Flows to Firm Method, we randomly chose an organization within Real Estate segment.

The procedure considered all aspects that may influence the precision of the calculation, i.e. a large scale of variability of calculating the enterprise value and essential variables to determine the discount rate. Honque and Rakow [13] argue that we also must take into account the ability of the management to achieve high performance and free cash flows. 
If the discount rate arose only from WACC calculation from equity costs from CAPM, the foreign capital and capital structure, there could be a risk of an inadequate assessment of the discount rate value. What might potentially cause this fault would be measuring the risk by CAPM, which indicated a slight deficiency, as the risk rate is an inevitable part of all investments. The risk rate, therefore, requires quantification.

A different decisive factor is the number of periods involved in the first step of assessing the enterprise value. Their lower number negatively influences the final price, as they do not inform on the perpetual growth of the company. The positive effect would be discernible in the event of recalculating the whole development of the monitored periods since the company's foundation.

The evaluated enterprise met all the decisive parameters. The method's applicability strongly depends on a precise calculation. Valuation of enterprises presents a comprehensive discipline established on appraiser's understanding not only the evaluated organization but also other external influences involved.

The validity of the result depends on the data available to the appraiser. His ability to predict the stability (or instability) of the development of the market economy is vital.

\section{Conclusion}

The goal was achieved. The method for evaluating an enterprise by free cash flows applied to a randomly selected corporation (small or medium-sized) within the designated segment.

The findings showed that valuation standards comply with value standards; the enterprise price agrees with the qualified estimate. Throughout the experiment of setting a discount rate and risk premium, we found out common contact points relating to enterprise capital value regarding the risk for its current shareholders and potential investors.

The selected enterprise met all required parameters for setting the enterprise value. The method used in this study has qualifications regarding the precision of the calculation. However, we can expect its application upon necessary modifications. On the other hand, some computations may give grounds for further research. The risk rate presents an issue for in-depth analysis and could become a central topic of another scholarly article.

Findings relating to the applicability of the technique in questions can serve as appraisers' decision-making criteria or clues for data collection to evaluate the enterprise. We may predict its higher potential for owners who want to know the up-to-date value of their companies and dispose of fresh and accurate information and data.

The research revealed that evaluating assets of enterprises mostly involves yield methods to fix the discount rate of the company. Disregarding the risk rate when pricing the enterprise and ignoring the value of risk premium of the discount rate may result in a simplification, as the amount of risk premium of the discount rate provides useful information for determining a discount rate within the project management's investment decision-making.

\section{References}

1. T. Kliestik, J. Vrbka, Z. Rowland, Bankruptcy prediction in Visegrad group countries using multiple discriminant analysis. Equilibrium-Quarterly Journal of Economics and Economic Policy, 13(3), 569-593 (2018)

2. S. Haskova, P. Suler, V. Machova, T. Krulicky, Determining the price of the business share of a business in a group. Ad Alta: Journal of Interdisciplinary Research, 9(2), 6070 (2019) 
3. M. Vochozka, V. Stehel, Z. Rowland, Determining development of business value over time with the identification of factors. Ad Alta: Journal of Interdisciplinary Research, 9(2), 358-363 (2019)

4. Z. Rowland, V. Machova, J. Horak, J. Hejda, Determining the market value of the enterprise using the modified methodof capitalized net incomes and Metfessel allocation of input data. Ad Alta: Journal of Interdisciplinary Research, 9(2), 305-310 (2019)

5. M. Vochozka, Z. Rowland, P. Suler, The specifics of valuating a business with a limited lifespan. Ad Alta: Journal of Interdisciplinary Research, 9(2), 339-345 (2019)

6. M. Vochozka, V. Machova, Determination of value drivers for transport companies in the Czech Republic. Nase More, 65(4), 197-201 (2018)

7. V. Machova, J. Horak, Value generators in forestry and logging. SHS Web of Conferences: Innovative Economic Symposium 2019 - Potential of Eurasian Economic Union (2020)

8. Y. Dong, Enterprise value evaluation based on FCFF model - A case analysis of Beixinyuan company. Proceedings of the 2nd International Conference on Economics and Management, Education, Humanities and Social Sciences (EMEHSS 2018), 151, pp. 615-620 (2018)

9. N. Zhang, The effects of anticipated future investments on firm value: evidence from mergers and acquisitions. Review of Accounting Studies, 21(2), 516-558 (2016)

10. K. Valaskova, T. Kliestik, M. Kovacova, Management of financial risks in Slovak enterprises using regression analysis. Oeconomia Copernicana, 9(1), 105-121 (2018)

11. T. Kliestik, K. Valaskova, G. Lazaroiu, M. Kovacova, J. Vrbka, Remaining financially healthy and competitive: The role of financial predictors. Journal of Competitiveness, 12(1), 74-92 (2020)

12. Kovacova, M., T. Kliestik, K. Valaskova, P. Durana, Z. Juhaszova, Systematic review of variables applied in bankruptcy prediction models of Visegrad group countries. Oeconomia Copernicana, 10(4), 743-772 (2019)

13. M. Hoque, K. Rakow, Do voluntary cash flow disclosures and forecasts matter to value of the firms? Managerial Finance, 42(1), 3-12 (2016)

14. I. Shaik, On the examination of value-based performance measures: Evidence from Indian firms. Springer Proceedings in Business and Economics, pp. 527-535 (2017)

15. N. R. Abramishvili, N. A. Lvova, N. S. Voronova, A.V. Kazansky, Free cash flow potential in assessing financial stability of nonfinancial businesses (the case of Russia). Proceedings of the 30th International Business Information Management Association Conference (IBIMA), 1-9, pp. 1376-1385 (2017)

16. P. Mielcarz, F. Mlinaric, The superiority of FCFF over EVA and FCFE in capital budgeting, Economic research, 27(1), 559-572 (2014)

17. D. Aharon, Y. Kroll, S. Riff, Degree of free cash flow leverage. Review of Accounting and Finance, 18(3), 346-365 (2019)

18. U. Yaari, A. Nikiforov, E. Kahya, Y. Shachmurove, Finance methodology of free cash flow. Global Finance Journal, 29, 1-11 (2016)

19. S. Kim, S. Park, J. Suh, A J-shaped cross-sectional relation between dividends and firm value. Journal of Corporte Finance, 48, 857-877 (2018)

20. E. Hendrawaty, Value of excess cash holdings of financially unconstrained companies. Contemporary Economics, 13(3), 293-303 (2019) 
21. C. Mari, M. Marra, Valuing firm's financial flexibility under default risk and bankruptcy costs: A WACC based approach, International Journal of Managerial Finance, 27(1), 688-699 (2019) 